\title{
EXPERIÊNCIA DO CURSO DE ENFERMAGEM DA UNIVERSIDADE FEDERAL DO CEARÁ SOBRE A APLICAÇÃO DA ANÁLISE PROSPECTIVA
}

\author{
Maria Josefina da Silva* \\ Lorita Marlena Freitag Pagliuca**
}

Relato da Aplicação da Análise Prospectiva do Curso de Enfermagem da Universidade Federal do Ceará, salientando a adequação do método às especialidades regional, local e institucional. Foi adotado como marco teórico "Saúde Como Direito Inerente à Cidadania" e a Enfermagem, para atingir marco, tem como estratégia o processo de CUIDAR, o que norteou a elaboração dos Marcos conceitual e referencial do curso e o perfil profissional do egresso.

\footnotetext{
* Professora Auxiliar de Ensino, Curso de Enfermagem da Universidade Federal do Ceará.

** Professora Titular de Enfermagem Fundamental, Curso de Enfermagem da Universidade Federal do Ceará.
} 